\title{
Coronary atherosclerosis - A postmortem histopathological study
}

\author{
Kumar $\mathrm{S}^{1}$, Kumar Verma $\mathrm{A}^{2}$, Kumar $\mathrm{N}^{3}$, Baranwal RK ${ }^{1}$, Kumar Verma $\mathrm{R}^{3}$, Singh $\mathrm{M}^{2}$ \\ Department of Forensic Medicine and Toxicology, B.R.D. Medical College, Gorakhpur (U.P.), India. \\ navneetchauhan@hotmail.com
}

\begin{abstract}
Cardiovascular disease in general and coronary heart disease in particular remains the leading cause of morbidity and mortality in developed countries. The aim of this study was to look at the prevalence of coronary atherosclerosis, its severity and site of involvement in postmortem hearts. The hearts of 30-60 yrs old, fifty dead victims were considered who died from various natural and unnatural deaths. After autopsy, coronary arteries were inspected grossly and microscopically. Out of all these cases, 10 cases (20\%) showed no pathological lesions. Total distribution of lesions in the coronaries are as follows; $34(68 \%)$ atheromatous lesions in Left Anterior Descending Artery, 25 (50 \%) lesions in the Right Coronary Artery, 18 (36 \%) lesions in Left Circumflex. Proximal involvement was more common except in the right coronary artery, which was involved distally. The overall prevalence of coronary atherosclerosis in the present study was comparable with that noted by other investigators in autopsy studied. There is a higher prevalence of atherosclerosis in Indians, which may be due to changes in life-styles and other risks factors (Tab. 1, Ref. 14). Full Text in PDF www.elis.sk.

Key words: coronary arteries, atherosclerosis, histopathology, autopsy, non-cardiac trauma.
\end{abstract}

The risk of Coronary Artery Disease in Indians is 3-4 times higher than in White Americans, 6-times higher than Chinese, and 20-times higher than in Japanese (1). The prevalence of Coronary Artery Disease is two-times higher (10\%) in urban than in rural India, South Indians have a higher prevalence, $7 \%$ in rural and $14 \%$ in urban areas (2).

The vulnerability of urban Indians to Coronary Artery Disease is possibly related to different nutritional environmental and lifestyle factors. Therefore, there has to be a high index of suspicion for Coronary Artery Disease in Indians above the age of 30 years. The prevalence of atherosclerosis in coronary arteries was noted to be $89.18 \%$ to $8.9 \%$, in the postmortem study $(3,4,5)$. Studies from the India on the nature and prevalence of occlusive coronary artery diseases are limited, while the risk factors for coronary atherosclerosis like hypertension, diabetes, cigarette smoking and high cholesterol diets are sharply rising in the developing world (6). The present study was undertaken to determine the prevalence of atherosclerosis in coronary arterial systems with special reference to the anatomical site of lesions in autopsy cases from north India.

\section{Material and methods}

The study was conducted on 50 human hearts at the Department of Forensic Medicine \& Toxicology and associated Mortuary,

\footnotetext{
${ }^{1}$ Department of Forensic Medicine and Toxicology, B.R.D. Medical College, Gorakhpur (U.P.), India, ${ }^{2}$ Department of Forensic Medicine and Toxicology, C.S.M. Medical University, Lucknow (U.P.) India, and ${ }^{3}$ Department of Anatomy, C.S.M. Medical University, Lucknow (U.P.) India

Address for correspondence: N. Kumar, MD, Department of Anatomy, C.S.M. Medical University, Lucknow (U.P.) India - 226003.

Phone: +91.9415083580
}

C.S.M., Medical University, Lucknow, during September 2008 to August 2009. A total 50 hearts were procured form postmortem bodies of both sexes in the age group 30-60 years, having a history of deaths due to natural as well as unnatural causes (accidental, suicidal, homicidal, etc.). The cases included were brought to the mortuary of the department within 12 hours of death, for the autopsy examination. Decomposed bodies were not considered for the study.

The Hearts were dissected out with a portion of ascending aorta from fresh bodies, on which postmortems were conducted at the departmental mortuary. The specimens were fixed in $10 \%$ formalin solution for 2-5 days. Identified segments of the coronary arteries viz. left anterior descending coronary artery, left circumflex artery and right coronary artery were sectioned at 3-mm intervals and stained with Haematoxylin \& Eosin and examined microscopically at 40x magnification, then, each section was examined; the intimal changes, atherosclerotic changes and approximate luminal narrowing (in percentage of luminal area) were noted. The degree of atherosclerosis was taken as the percentage of the cross-sectional area of occlusion of the lumen at the maximum point of occlusion of the respective artery. Photomicrographs of the sections were taken.

\section{Observations}

Out of total 50 cases studied, the manner of death was Natural in 35 cases, Accidental in 7 cases, Suicidal in 5 cases and Homicidal in 3 cases.

Out of these cases, 10 cases (20\%) showed no pathological lesions, 8 cases ( $16 \%$ ) showed a minimal intimal thickening with atherosclerotic lesions and luminal narrowing of $\leq 25 \%$ of luminal 
Tab. 1. Distribution of Atheroma in Coronary Arteries.

\begin{tabular}{lcccc}
\hline $\begin{array}{l}\text { Coronary } \\
\text { artery }\end{array}$ & $\begin{array}{c}\text { Proximal } \\
\text { 3rd }\end{array}$ & $\begin{array}{c}\text { Middle } \\
\text { 3rd }\end{array}$ & $\begin{array}{c}\text { Distal } \\
\text { 3rd }\end{array}$ & Total \\
\hline $\begin{array}{l}\text { Left Anterior } \\
\text { Descending artery }\end{array}$ & 21 & 11 & 2 & $34(68 \%)$ \\
\hline $\begin{array}{l}\text { Left Circumflex } \\
\text { artery }\end{array}$ & 11 & 6 & 1 & $18(36 \%)$ \\
\hline $\begin{array}{l}\text { Right Coronary } \\
\text { artery }\end{array}$ & 5 & 7 & 13 & $25(50 \%)$ \\
\hline
\end{tabular}

diameter, 12 cases (24\%) showed a moderate intimal thickening with atherosclerotic changes and luminal narrowing $\leq 50 \%$ of luminal diameter, in 20 cases ( $40 \%$ ) there was a marked intimal thickening with atherosclerotic changes and luminal narrowing $\leq$ $75 \%$ of luminal diameter.

In the Left Anterior Descending Artery, out of 34 atheromatous lesions, $21(61.76 \%)$ various types of lesions were seen in the proximal $3 \mathrm{rd}, 11(32.35 \%)$ lesions of various types in the middle 3rd, while only $2(5.88 \%$ ) lesions were seen in the distal $3 \mathrm{rd}$ of the Left Anterior Descending Artery.

In the Left Circumflex artery, out of 18 lesions, 11 (61.11\%) lesions of various types were seen in the proximal $3 \mathrm{rd}, 6(33.33 \%)$ lesions of various types in the middle 3rd, while only 1 (5.56\%) lesion was seen in the distal 3rd of the Left Circumflex .

In the Right Coronary Artery, out of 25 lesions, 5 (20\%) lesions of various types were seen in the proximal $3 \mathrm{rd}, 7$ (28\%) lesions of various types in the middle $3 \mathrm{rd}$, while in the distal $3^{\text {rd }}$, $13(52 \%)$ lesions of various histological types were seen in the Right Coronary Artery .

The total distributions of lesions in the coronaries are as follows; 34 (68\%) atheromatous lesions in the Left Anterior Descending Artery, 25 (50\%) lesions in the Right Coronary Artery \& 18 (36\%) lesions in the Left Circumflex artery (Tab. 1).

The most common site of lesion was the proximal 3rd of Left Anterior Descending Artery (61.76\%) and the Left Circumflex artery $(61.11 \%)$ while in case of the Right Coronary Artery, maximum lesions were seen in the distal 3rd of the artery (52\%).

\section{Discussion}

The coronary artery arthrosclerosis has been evaluated vigorously in all groups of people in postmortem studies. Sudden coronary death (SCD) in older individuals is generally associated with an extensive coronary atherosclerosis, although it may be the first manifestation of ischemic heart disease. In younger age groups, SCD may occur in the presence of less severe disease. Victims of SCD had significantly more severe atherosclerosis in major coronary arteries per subject with luminal area narrowing $\geq 75 \%$. The arterial thrombosis most often with an underlying plaque rupture was the mechanism of SCD in $>80 \%$ of the cases, considering histological sections with $\geq 50$ and with $\geq 75 \%$ area of stenosis (3). In the autopsy study, among 124 men (age range 50 to 69 years) who died of non cardiac causes, $10.3 \%$ had onevessel, $2.8 \%$ had two-vessel, and $1.4 \%$ had three-vessel coronary disease (7). Also, active coronary lesions have been observed in cases of noncardiac sudden death; plaque fissure and intra intimal thrombi (without intraluminal thrombus) were present in $8.9 \%$ of 69 cases of non cardiac sudden death (5). In a recent study, sudden cardiac death was attributed to one-vessel disease in 33 of 37 young persons, with coronary thrombosis noted in $27 \%$ (4). Autopsies performed on casualties of the Korean War revealed coronary artery involvement in $77.3 \%$ of the hearts studied and data after the Vietnam War noted the presence of atherosclerosis in 45 $\%$ of casualties with severe disease in $5 \%$. One hundred eleven victims of noncardiac trauma underwent pathologic examination of their coronary arteries to estimate the presence and severity of coronary atherosclerosis. Signs of coronary atherosclerosis were seen in $78.3 \%$ of the total study group (8). These findings are analogous with our results. The observations of the present study indicate that atheromatous lesions in the Left Anterior Descending Artery, Right Coronary Artery and Left Circumflex artery are $34(68 \%), 25(50 \%)$ and $18(36 \%)$, respectively.

Variable data were noted also by other investigators. In 1000 cases of "natural" unexpected sudden death, less than 65 years old were examined, in which 448 potentially lethal lesions were detected, out of which 407 cases corresponded to coronary disease (9). 2,709 fatalities among road users, arising from a total 59,164 accidents resulting in injury or death from year 1983 to1992 in Singapore showed that 1,134 and 904 deaths involved drivers of motor vehicles and motorcyclists, respectively. In 13 cases of former and 2 of latter, death was deemed to have occurred naturally as a consequence of ischemic heart disease (10).

In the in vivo intra-vascular USG study in heart transplant recipients, the prevalence of atherosclerosis varied from $17 \%$ in individuals $<20$ years old to $85 \%$ in subjects $\geq 50$ years old (11).

The $16 \%$ of hearts had evidence of atherosclerosis visible to the naked eye. Over $50 \%$ luminal narrowing was observed in the 12 vessels with the majority in the Left Anterior Descending Artery. Only two vessels had over $75 \%$ narrowing (12).

Proximal involvement was more common except in the right coronary artery, which was frequently involved distally (8).We also found that the proximal 3rd of Left Anterior Descending Artery $(61.76 \%)$ and Left Circumflex artery $(61.11 \%)$ have maximum lesions while in the case of the Right Coronary Artery, maximum lesions were seen in the distal 3rd of the artery (52\%).

Complex atheromatous lesions consisting of plaques with defined necrotic cores include fibroatheromas, rupture prone (thin-cap fibroatheromas), acute and healing ruptures, and lesions complicated by intraplaque hemorrhage. These plaques were predominantly found in the proximal portions of the left anterior descending, left circumflex, and the mid-portion of the right artery (13). This anatomic relationship is not a coincidence because many lesions occur near flow dividers as there is an ample evidence to suggest that atherosclerotic lesion size and vulnerability can be manipulated by changing patterns of blood flow (14). Finally, we conclude that $80 \%$ of the Indian hearts are affected with coronary atherosclerosis, which is a much higher prevalence when compared to the rest of world population. The proximal $1 / 3$ of the Left Anterior Descending Artery is most commonly involved in atherosclerosis. 


\section{References}

1. Enas EA. High rates of CAD in Asian Indians in the United States despite intensive modification of life style. What next. Current Science 1998; 74.

2. Bhatia ML. Prevalence of CAD in India: A contemporary view. Indian Heart J 1995; 47: 339-342.

3. Schmermund A, Schwartz RS, Adamzik M, Sangiorgi G, Pfeifer EA, Rumberger JA, Burke AP, Farb A, Virmani R. Coronary atherosclerosis in unheralded sudden coronary death under age 50: histo-pathologic comparison with 'healthy' subjects dying out of hospital. Atherosclerosis 2001; 155 (2): 499-508.

4. Corrado D, Basso C, Poletti A, Angelini A, Valente M, Thiene G. Sudden death in the young: is acute coronary thrombosis the major precipitating factor? Circulation 1994; 90: 2315-2323.

5. Davies M, Bland J, Hangartner J, Angelini A, Thomas A. Factors influencing the presence or absence of acute coronary artery thrombi in sudden ischemic death. Eur Heart J 1989; 10: 203-208.

6. Dzavick, $\mathbf{V}$. The need for revascularization procedures will remain the same or increase in the next decade. Canad J Cardiol 1998; 14 (Suppl A): $27 \mathrm{~A}-31 \mathrm{~A}$.

7. Thomas AC, Knapman PA, Kirkler DA, Davies MJ. Community study of the causes of 'natural' sudden death. Br Med J 1988; 297: 1453-1456.
8. Joseph A, Ackerman D, Talley JD, Johnstone J, Kupersmith J. Manifestations of coronary atherosclerosis in young trauma victims--an autopsy study. J Am Coll Cardiol 1993; 22 (2): 459-467.

9. Tabib A, Loire R. Unexpected sudden death and coronary lesions. Apropos of 407 cases out of 1000 deaths in patients under 65 years of age. Arch Mal Coeur Vaiss 1993; 86 (4): 401-406.

10. Lau G. Ischaemic heart disease as a natural cause of death in Motorists. Singapore Med J 1994; 35: 467-470.

11. Tuzku EM, Kapadia SR, Tutar E, Ziada KM, Habbs RE, Mc Carthy PM, Young JB, Nissen SE. High prevalence of coronary atherosclerosis in asymptomatic teenagers and young adults: evidence from intravascular ultrasound. Circulation 2001; 103 (22): 2705-2710.

12. Saidi HS, Olumbe HOK, Kalebi A. Anatomy and pathology of coronary arteries in adult black kenyans. East African Med J 2002; 79 (6): 323-327.

13. Kolodgie FD, Burke AP, Frab A, Gold HK, Yuan J, Narula J, Finn AV, Virmani R. The thin cap fibroartheroma; a type of vulnerable plaque :the major Precursor lesion to acute coronary syndromes. Curr Opin Cardiol 2001; 16: 285-292.

14. Cheng C, Tempel D, Van Haperen R, van der Been A, Grsoveld F, Deamen MJ, Karmas R, de Crom R. Atherosclerotic lesion size and vulnerability are determined by pattern fluid shear stress. Circulation 2006; 113: $2744-2753$. 